\title{
Promoting research on wellbeing
}

\author{
Dan Weijers · Aaron Jarden · Nattavudh Powdthavee
}

\section{Welcome}

Welcome to the inaugural issue of the International Journal of Wellbeing (IJW). The IJW is an open access peer-reviewed journal that publishes scholarly research on wellbeing (broadly construed). The purpose of the journal is to promote thought and discussion on this vital topic. The launch of the IJW is a direct response to increasing demand both for research on wellbeing and for publishing opportunities for wellbeing researchers. Several established academic journals already publish research on wellbeing, most notably the Journal of Happiness Studies, Social Indicators Research, Applied Psychology: Health and Well-being, The Journal of Positive Psychology, Quality of Life Research, Applied Research in Quality of Life, the International Journal of Qualitative Studies on Health and Wellbeing, and the forthcoming open access journal Psychology of Wellbeing: Theory, Research and Practice. However, none of these journals provides the combination that is the IJW's most striking attribute: a broad multidisciplinary scope, an interdisciplinary focus, and a commitment to provide all its content for free without delay or any cost to authors.

\section{About the editorial team}

Although the editors approach wellbeing research from their respective disciplines philosophy, psychology, and economics - their shared passion for open access interdisciplinary wellbeing research brought them together to develop the IJW. As it turned out, many of the most influential thinkers in the field felt that an open access interdisciplinary journal on wellbeing was worth supporting. Despite being edited by three early-career academics, over 50 leading wellbeing researchers have joined the IJW team as Consulting Editors or Section Editors. Our large editorial team includes researchers from philosophy, psychology, economics, and other disciplines with an interest in wellbeing. This enables the IJW to review and publish a wide range of wellbeing-related research, including interdisciplinary research.

\section{The importance of open access and interdisciplinary wellbeing research}

The IJW intends to take advantage of an academic environment that is increasingly aware of the need for open access publishing and the benefits of interdisciplinary research. Readers of the IJW will enjoy free access to a wide range of the latest research on wellbeing. Authors who publish in the IJW will make a contribution to the dissemination of free research on wellbeing without paying anything; and will benefit from having work published in a top quality blind peer-reviewed journal.

Open access publication of research has many benefits. The time and expense required to track down research in journals with subscription fees prevents many academics from 
productively joining the discourse they are investigating. These restrictions discriminate against the scholars who are already worst off, and ultimately slow the pace of academic progress. Furthermore, subscription fees make it harder for wellbeing practitioners, such as clinical psychologists and coaches, to put new research to good use. Publishing with an open access journal used to be thought of as risky - something that only established researchers would consider - but that is no longer the case. Many studies have investigated the impact of open access publications, the most careful of which found that open access publications receive about as many citations as research published in subscription-only journals. There is at least one exception to this general rule, however; in poorer countries, open access articles are downloaded and cited more frequently than those published in subscription-only journals. ${ }^{1}$

As is perhaps much better known, interdisciplinary research also has considerable benefits. When researchers from diverse disciplines collaborate on a topic, they must first establish the overlap and disconnects between the established knowledge from each discipline. Working through the disciplinary similarities and differences enables the collaborators to create a broader, more nuanced, and more accessible understanding of the topic. Furthermore, if this collaborative understanding is reported, other researchers can use the resulting information as a guide to incorporating the findings of the other discipline(s) into their own investigations. Researchers who draw on findings from other disciplines in this way can bring new and often fruitful perspectives to their discipline's old problems and new challenges. Performed in this way, interdisciplinary research has the potential to produce disciplinary advances much faster than if researchers never looked outside of their respective disciplines. ${ }^{2}$ Since the public has a stake in any wellbeing research with practical implications, it too will benefit from these advantages of interdisciplinary research on wellbeing.

\section{Aims, scope, and points of difference}

The IJW aims to make the most significant research in wellbeing accessible to all in a timely manner. Although we expect most submissions to be from a mainly philosophical, psychological or economic perspective, we are particularly interested in publishing interdisciplinary wellbeing research. The IJW aims to be the first choice for authors whose research draws on findings from two or more of the three disciplines mentioned above and any other relevant disciplines such as neuroscience, epidemiology, public policy, and sociology.

The IJW aims to make the review and publishing process as fast as possible for authors without reducing the quality of the review or copyediting processes. The $I J W^{\prime} s$ blind reviewers are expected to return comments within four weeks. Furthermore, because the IJW is an onlineonly journal, and uses an unconstrained 'rolling issue' process, accepted submissions will be available much faster than they would with most existing journals.

Along with research articles, the IJW will publish meta-analyses, review articles, critical notices, book reviews, interviews with established wellbeing researchers, and special issues. The IJW also plans to publish a diverse range of multimedia content, including readers' comments on IJW articles, video abstracts, and debates.

The $I J W^{\prime}$ 's main point of difference, however, is that it is the only journal on wellbeing that incorporates full open access, broad multidisciplinary scope, and an interdisciplinary focus.

\footnotetext{
${ }^{1}$ Evans, J. \& Reimer, J. (2009). Open access and global participation in science. Science, Vol. 323 no. 5917, (20 February 2009), p. 1025. DOI: $10.1126 /$ science. 1154562

2 Wilson, E. O. (1998). Consilience: The unity of knowledge. Knopf: New York.
} 


\section{Authors}

\section{Dan Weijers}

Victoria University of Wellington

dan.weijers@vuw.ac.nz

\section{Aaron Jarden}

Open Polytechnic of New Zealand

aaron.jarden@openpolytechnic.ac.nz

Nattavudh Powdthavee

Nanyang Technological University

n.powdthavee@ntu.edu.sg

\section{References}

Evans, J. \& Reimer, J. (2009). Open access and global participation in science. Science, Vol. 323 no. 5917, (20 February 2009), p. 1025. http://dx.doi.org/10.1126/science.1154562

Wilson, E. O. (1998). Consilience: The unity of knowledge. Knopf: New York. 